\title{
UJI STASIONERITAS DATA INFLASI DENGAN PHILLIPS-PERON TEST
}

\author{
Di Asih I Maruddani ${ }^{1)}$, Tarno ${ }^{1)}$, Rokhma Al Anisah ${ }^{2)}$ \\ ${ }^{1)}$ Program Studi Statistika, Jurusan Matematika, FMIPA, UNDIP \\ ${ }^{2)}$ Alumni Prodi Statistika, Jurusan Matematika, FMIPA, UNDIP
}

\begin{abstract}
The classical regression model was devised to handle relationships between stationary variables. It should not be applied to nonstationary series. A time series is therefore said to be stationary is its mean, variance, and covariances remain constant over time. A problem associated with nonstationary variables, and frequently faced by econometricians when dealing with time series data, is the spurious regression. An apparent indicator of such spurious regression was a particularly low level for the Durbin-Watson statistics, combined with an acceptable $\mathrm{R}^{2}$. Statistical test for stationarity have proposed by Dickey and Fuller (1979). The distribution theory supporting the Dickey-Fuller test assumes that the errors are statistically independent and have a constant variance. Phillips and Peron (1988) developed a generalization of the Dickey-Fuller procedure that the error terms are correlated and not have constant variance. In this paper, we use Phillips-Peron test for inflation data in Indonesia for the time period 1996-2003. The data showed upward trend and the error terms are correlated. The empirical results showed that the inflation data in Indonesia is a nonstationary series.
\end{abstract}

Keywords : stationarity, non autocorrelation, Phillips-Peron Test, inflation

\section{Pendahuluan}

Dalam analisis ekonometrika, adanya hubungan keseimbangan jangka panjang antara variabel-variabel yang berhubungan sangat diperlukan untuk melakukan peramalan. Hasil peramalan ini sangat berguna sebagai alat pengambilan keputusan. Hubungan jangka panjang tersebut dapat diketahui melalui pendekatan kointegrasi. Kointegrasi merupakan hubungan antara variabel-variabel yang stasioner pada derajat yang sama. Sehingga stasioneritas merupakan syarat yang penting dalam pendekatan kointegrasi.

Apabila variabel yang digunakan tidak stasioner akan menyebabkan hasil regresi meragukan atau disebut regresi lancung (spurious regression). Regresi lancung adalah situasi dimana hasil regresi menunjukkan koefisien regresi yang signifikan dan nilai koefisien determinasi yang tinggi namun hubungan antara variabel independen dan variabel dependen di dalam model tidak saling berhubungan ${ }^{[4]}$. Hal ini terjadi karena hubungan keduanya yang merupakan data time series hanya menunjukkan trend saja. Untuk melakukan uji stasioneritas digunakan uji akar unit.

Uji akar unit mula-mula dikembangkan oleh D.A. Dickey dan W.A. Fuller yang dikenal sebagai uji akar unit Dickey-Fuller ${ }^{[2]}$. Uji akar unit Dickey-Fuller mengasumsikan bahwa residual $e_{t}$ adalah residual yang bersifat independen dengan rata-rata nol, varian konstan, dan tidak saling berhubungan (non autokorelasi). Akan tetapi dalam banyak kasus, residual $e_{t}$ sering kali saling berhubungan atau mengandung unsur autokorelasi. Sehingga perlu dikembangkan uji akar unit terhadap data yang mengandung autokorelasi pada residual $e_{t}$.

\section{Bahan dan Metode \\ 2.1 Bahan}

Permasalahan inflasi merupakan fokus penting bagi pemerintah pada saat keadaan ekonomi yang tidak stabil akhir-akhir ini. Inflasi adalah kecenderungan dari harga-harga untuk menaik secara umum dan terus menerus. Untuk mengetahui tinggi rendahnya harga 
atau laju inflasi sering digunakan indeks harga. Salah satu cara yang sering digunakan adalah menggunakan nilai indeks harga konsumen. Indeks harga konsumen (IHK) adalah perbandingan relatif dari paket komoditas dibandingkan dengan harga-harga komoditas tersebut pada suatu saat tertentu yang digunakan pada suatu tahun dasar.

Penyelesaian masalah dengan data inflasi yang tidak memperhatikan sifat stasioneritas mengakibatkan segala keputusan yang terkait dengan data inflasi menjadi tidak valid. Untuk itu akan diuji data inflasi di Indonesia periode tahun 1996-2003. Data yang digunakan adalah data sekunder runtun waktu kuartalan yang diperoleh dari Statistik Ekonomi dan Keuangan Indonesia yang diterbitkan oleh Bank Indonesia (BI) ${ }^{[1]}$. Alasan pemilihan rentang waktu adalah karena keterbatasan penggunaan angka tahun dasar pada data IHK, sehingga diambil satu tahun dasar yaitu tahun dasar $1996=100$ yang dimulai dari tahun 1996.I sampai dengan 2003.IV.

\subsection{Metode}

Runtun waktu $\left\{Y_{t}\right\}$ dikatakan stasioner jika distribusi bersama dari $\left(Y_{t 1}, \ldots, Y_{t k}\right)$ identik dengan $\left(Y_{t 1+t}, \ldots, Y_{t k+t}\right)$ untuk semua t, dimana $\mathrm{k}$ adalah sembarang integer positif. Dengan kata lain dalam keadaan stasioner distribusi bersama $\left(Y_{t 1}, \ldots, Y_{t k}\right)$ adalah sama dalam satu waktu.

Runtun waktu $\left\{Y_{t}\right\}$ dikatakan stasioner lemah jika kedua rata-rata $Y_{t}$ dan kovarian antara $Y_{t}$ dan $Y_{t-1}$ adalah konstan terhadap waktu. Sifat proses stasioner lemah adalah ${ }^{[13,15] \text {. }}$

$$
\begin{aligned}
& E\left(Y_{t}\right)=\mu \\
& \operatorname{Cov}\left(Y_{t}-Y_{t-1}\right)=\gamma_{t} \\
& \operatorname{Var}\left(Y_{t}\right)=\gamma_{0}
\end{aligned}
$$

Pada prakteknya, misalkan dipunyai observasi $\mathrm{T}$ data $=\left\{Y_{t} \mid t=1, \ldots, \mathrm{T}\right\}$, stasioner lemah menunjukkan bahwa plot data memberikan nilai $\mathrm{T}$ berfluktuasi dengan varian konstan di sekitar nilai yang tetap. Dengan kata lain data runtun waktu dikatakan stasioner jika rata-rata, varian, dan kovarian pada setiap lag adalah tetap sama pada setiap waktu. Jika data runtun waktu tidak memenuhi kriteria tersebut maka data dikatakan tidak stasioner. Data runtun waktu dikatakan tidak stasioner jika rata-ratanya maupun variannya tidak konstan, berubah-ubah sepanjang waktu (time-varying mean and variance) ${ }^{[14]}$.

Akar unit adalah suatu cara untuk menguji stasioneritas. Pada prinsipnya uji akarakar unit dimaksudkan untuk mengamati apakah koefisien tertentu dari model yang ditaksir mempunyai nilai satu atau tidak.

Ide dasar uji stasioneritas data melalui uji akar unit dapat dijelaskan melalui model AR (1) di bawah ini ${ }^{[8],[9]}$ :

$$
Y_{t}=\alpha Y_{t-1}+e_{t} \quad-1 \leq \alpha \leq 1
$$

dimana $e_{t}$ adalah residual yang bersifat random atau stokastik dengan rata-rata nol, varian konstan, dan tidak saling berhubungan (non autocorrelation) sebagaimana asumsi metode OLS. Residual yang mempunyai sifat tersebut disebut residual yang white noise.

Jika nilai $\alpha=1$ maka variabel random (stokastik) $Y$ mempunyai akar unit (unit root). Jika data runtun waktu mempunyai akar unit maka dikatakan data tersebut bergerak secara random (random walk) dan data yang mempunyai sifat random walk dikatakan data tidak stasioner.

Jika persamaan (2.4) dikurangi kedua sisinya dengan $Y_{t-1}$ maka akan diperoleh persamaan : 


$$
\begin{aligned}
Y_{t}-Y_{t-1} & =\alpha Y_{t-1}-Y_{t-1}+e_{t} \\
& =(\alpha-1) Y_{t-1}+e_{t}
\end{aligned}
$$

Persamaan (2.5) di atas dapat ditulis sebagai berikut :

$$
\Delta Y_{t}=\phi Y_{t-1}+e_{t}
$$

dimana $\phi=(\alpha-1)$ dan $\Delta Y_{t}=Y_{t}-Y_{t-1}$

Untuk menguji ada tidaknya masalah akar unit dilakukan estimasi persamaan (2.6) dengan hipotesis nol $\phi=0$. Jika $\phi=0$ maka $\alpha=1$ sehingga data $Y$ mengandung akar unit yang berarti data runtun waktu $Y$ adalah tidak stasioner ${ }^{[13]}$.

\section{Hasil dan Pembahasan}

Untuk mengembangkan uji akar unit Dickey-Fuller pada permasalahan data dengan sifat autokorelasi pada residual, digunakan uji akar unit yang dikembangkan oleh Peter C.B. Phillips dan P.Perron. Uji ini dilakukan dengan menggunakan metode statistik nonparametrik dalam menjelaskan adanya autokorelasi antara residual tanpa memasukkan variabel independen kelambanan diferensi ${ }^{[16]}$.

Keuntungan menggunakan uji ini adalah asumsi bahwa tidak terdapat bentuk fungsi untuk variabel proses residual sehingga uji PP dikatakan uji non parametrik. Karena bersifat non parametrik maka uji PP dapat digunakan untuk banyak kasus dan pada sampel yang besar, uji PP akan menunjukkan hasil yang bagus. hipotesis

Uji stasioneritas dengan Uji Akar Unit Phillips-Perron (PP), dilakukan dengan

$$
\begin{aligned}
& \mathrm{H}_{0}: \alpha=1\left(Y_{t} \text { tidak stasioner }\right) \\
& \mathrm{H}_{1}: \alpha<1\left(Y_{t} \text { stasioner }\right)
\end{aligned}
$$

Sehingga apabila $\alpha=1$, maka runtun $Y_{t}$ tidak stasioner karena mempunyai akar unit. Untuk $\alpha=1$, persamaan (2.4) dapat ditulis :

$$
Y_{t}=Y_{t-1}+u_{t} \quad(t=1,2, \ldots)
$$

Untuk mendapatkan nilai estimasi $\alpha$ atau $\hat{\alpha}$ dilakukan dengan mempertimbangkan estimator kuadrat terkecil (least squares) terhadap model (2.4). Masing-masing sisi persamaan (2.4) dikalikan dengan $Y_{t-1}$, sehingga diperoleh:

$$
\begin{aligned}
& Y_{t} Y_{t-1}=\alpha Y_{t-1}^{2}+e_{t} \\
& e_{t}=Y_{t} Y_{t-1}-\alpha Y_{t-1}^{2}
\end{aligned}
$$

Jumlah kesalahan minimum dari residual kuadrat adalah:

$$
\sum_{t=1}^{T} e_{t}^{2}=\sum_{t=1}^{T}\left(Y_{t} Y_{t-1}-\alpha Y_{t-1}^{2}\right)^{2}=S
$$

Untuk mendapatkan nilai estimasi $\alpha$ digunakan turunan pertama dari $S$ dan menyamakannya dengan nol.

$$
\begin{aligned}
& \frac{\partial S}{\partial \hat{\alpha}}=-2 \sum_{t=1}^{T}\left(Y_{t} Y_{t-1}-\hat{\alpha} Y_{t-1}^{2}\right)=0 \\
& \Leftrightarrow \hat{\alpha}=\frac{\sum_{t=1}^{T} Y_{t-1}^{2}+\sum_{t=1}^{T} Y_{t-1} \Delta Y_{t}}{\sum_{t=1}^{T} Y_{t-1}^{2}}=1+\frac{\sum_{t=1}^{T} Y_{t-1} \Delta Y_{t}}{\sum_{t=1}^{T} Y_{t-1}^{2}}
\end{aligned}
$$


Sehingga

$$
T(\hat{\alpha}-1)=T\left(1+\frac{\sum_{t=1}^{T} Y_{t-1} \Delta Y_{t}}{\sum_{t=1}^{T} Y_{t-1}^{2}}-1\right)=T \frac{\sum_{t=1}^{T} Y_{t-1} \Delta Y_{t}}{\sum_{t=1}^{T} Y_{t-1}^{2}}
$$

masing-masing komponen pada sisi kanan persamaan di atas dibagi dengan $T$, sehingga diperoleh:

$$
T(\hat{\alpha}-1)=T \frac{\left(\sum_{t=1}^{T} Y_{t-1} \Delta Y_{t}\right) / T}{\left(\sum_{t=1}^{T} Y_{t-1}^{2}\right) / T}=\frac{\sum_{t=1}^{T}\left(Y_{t-1} / \sqrt{T}\right)\left(\Delta Y_{t} / \sqrt{T}\right)}{\sum_{t=1}^{T}\left(Y_{t-1} / \sqrt{T}\right)^{2} \frac{1}{T}}
$$

Dapat dilihat bahwa $Y_{t-1} / \sqrt{T}$ konvergen dengan gerak Brownian, dan dengan integral stokastik diperoleh ${ }^{[7]}$ :

$$
T(\hat{\alpha}-1) \Rightarrow \frac{\int_{0}^{1} W(r) d W(r)}{\int_{0}^{1} W(r)^{2} d r}
$$

Bentuk di atas dikenal sebagai distribusi akar unit.

Nilai statistik $t$ untuk regresi (2.4) sebagai berikut :

$$
\begin{aligned}
& t_{\hat{\alpha}}=\frac{\hat{\alpha}-1}{s / \sqrt{\sum_{t=2}^{T} y_{t-1}^{2}}} \\
& t_{\hat{\alpha}}=\frac{\hat{\alpha}-1}{s / \sqrt{\sum_{t=2}^{T} Y_{t-1}^{2}-\frac{1}{T} \sum_{t=2}^{T}\left(Y_{t-1}\right)^{2}}}
\end{aligned}
$$

atau dapat ditulis :

$$
t_{\hat{\alpha}}=\frac{\phi}{\operatorname{se}(\hat{\phi})}
$$

dimana $s e(\hat{\phi})$ merupakan koefisien kesalahan standar untuk $\phi$ yang diberikan sebagai :

$$
\begin{aligned}
\operatorname{se}(\hat{\phi}) & =\sqrt{\frac{s^{2}}{\sum_{t=2}^{T} y_{t-1}^{2}}} \\
\operatorname{dan} s^{2} & =\frac{\sum_{t=2}^{T}\left(Y_{t}-\hat{\alpha} Y_{t-1}\right)^{2}}{T-1} .
\end{aligned}
$$

Persamaan (3.3) dan (3.5) sebagai uji statistik Dickey-Fuller untuk mendeteksi adanya akar unit pada regresi (2.4), dengan hipotesis nol $\alpha=1$ dan hipotesis alternatif $\alpha<1^{[10],[12]}$.

Phillips dan Perron ${ }^{[11]}$ mengusulkan metode alternatif nonparametrik untuk menguji serial korelasi dengan akar unit. Untuk menyelesaikan masalah parameter gangguan, digunakan estimator konstan untuk $\sigma_{u}{ }^{2}$ dan $\sigma^{2}$ untuk melakukan transformasi statistik $T(\hat{\alpha}-1)$ dan $t_{\hat{\alpha}}$ dengan cara menghilangkan pengaruh parameter gangguan. 
Estimator konstan untuk $\sigma_{u}{ }^{2}$ dinotasikan dengan $s_{u}{ }^{2}$, dimana $s_{u}{ }^{2}$ merupakan estimasi kesalahan standar pada persamaan regresi (2.4). Nilai $s_{u}{ }^{2}=$ $s^{2}=\frac{\sum_{t=2}^{T}\left(Y_{t}-\hat{\alpha} Y_{t-1}\right)^{2}}{T-1} \quad$ untuk data yang diturunkan oleh persamaan (2.4). Ketika $\left\{u_{t}\right\}$ stasioner lemah dengan kepadatan spektral $f_{u}(\lambda)$, diperoleh $\sigma^{2}=2 \pi f_{u}(0)$. Pada kasus ini estimator konstan untuk $\sigma^{2}$ sama dengan estimasi kepadatan spektral dari $\left\{u_{t}\right\}$ pada titik awal, yang dinotasikan dengan $S_{T l}^{2}$.

$$
S_{T l}^{2}=T^{-1} \sum_{t=1}^{T} u_{t}^{2}+2 T^{-1} \sum_{\tau=1}^{l} w_{\tau t} \sum_{t=\tau+1}^{T} u_{t} u_{t-\tau}
$$

dimana

$$
w_{\tau t}=1-\tau /(l+1)
$$

Dalam menentukan panjangnya lag, uji PP menggunakan truncation lag $l$ dari Newey-West. Jumlah $l$ menunjukkan periode adanya masalah autokorelasi. Jumlah $l$ dari Newey-West yang ditetapkan berdasarkan pada jumlah observasi dalam sampel dan diberikan oleh :

$$
l=\operatorname{int}\left(4(T / 100)^{2 / 9}\right)
$$

dimana int( ) menunjukkan bagian integer dari bilangan.

Dengan transformasi statistik $T(\hat{\alpha}-1)$ dan $t_{\hat{\alpha}}$ menggunakan estimator konstan dari $s_{u}^{2}$ dan $s_{T l}^{2}$ diperoleh statistik :

$$
Z_{\alpha}=T(\hat{\alpha}-1)-\frac{\left(s_{T l}^{2}-s^{2}\right)}{2 T^{-2} \sum_{t=2}^{T} y_{t-1}^{2}}
$$

dan

$$
\begin{aligned}
& Z_{t}=\frac{\sqrt{\sum_{t=2}^{T} y_{t-1}^{2}}(\hat{\alpha}-1)}{s_{T l}}-\frac{\frac{1}{2}\left(s_{T l}^{2}-s^{2}\right)}{s_{T l} \sqrt{T^{-2} \sum_{t=2}^{T} y_{t-1}^{2}}} \\
& Z_{t}=\frac{s}{s_{T l}} t_{\hat{\alpha}}-\frac{T\left(s_{T l}^{2}-s^{2}\right)(\operatorname{se}(\hat{\phi}))}{2 s_{T l} s}
\end{aligned}
$$

Untuk melakukan uji akar unit, nilai $Z_{t}$ di atas dibandingkan dengan nilai kritis dari Dickey-Fuller. Rumusan hipotesis diperoleh dengan mengestimasi persamaan (3.1) setelah dilakukan pengurangan pada kedua sisi persamaan dengan $Y_{t-1}$ dan menambahkan sebuah intersep $\mu$.

$$
\begin{gathered}
Y_{t}=\mu+\alpha Y_{t-1}+e_{t} \\
Y_{t}-Y_{t-1}=\mu+\alpha Y_{t-1}-Y_{t-1}+e_{t} \\
\Delta Y_{t}=\mu+(\alpha-1) Y_{t-1}+e_{t} \\
\Delta Y_{t}=\mu+\phi Y_{t-1}+e_{t}
\end{gathered}
$$

Hipotesa yang digunakan adalah

$\mathrm{H}_{0}: \phi=0$ ( $Y_{t}$ tidak stasioner $)$ 


$$
\mathrm{H}_{1}: \phi<0\left(Y_{t} \text { stasioner }\right)
$$

dimana $\phi=(\alpha-1)$.

Jika $\phi=0$ maka $\alpha=1$ sehingga data $Y$ mengandung akar unit yang berarti data runtun waktu $Y$ adalah tidak stasioner. Hipotesis nol ditolak bila nilai $Z_{t}$ lebih kecil dari nilai kritis statistik Dickey-Fuller yang berarti proses stasioner.

Uji akar unit Phillips-Peron ini akan diaplikasikan pada data inflasi di Indonesia pada periode tahun 1996-2003. Plot data inflasi diberikan pada gambar 3.1.

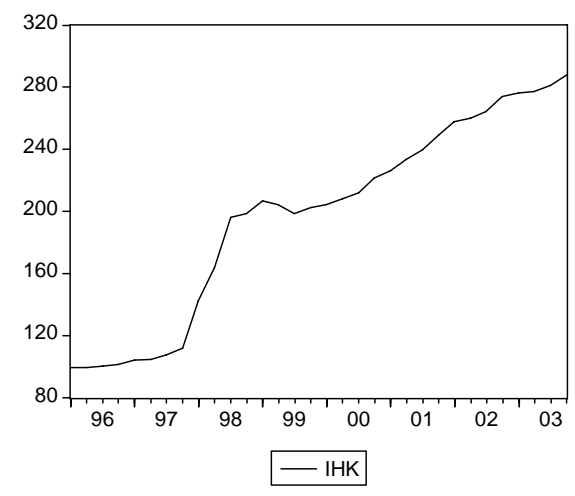

Gambar 3.1 Plot Data Inflasi Indonesia Periode 1996-2003

Sebelum dilakukan uji akar unit Phillips-Peron akan diuji terlebih dahulu keberadaan autokorelasi pada residual dengan menggunakan Breusch Godfrey Serial Correlation LM Test yang dihasilkan dari persamaan (3.13). Outputnya diberikan pada tabel 3.1

Tabel 3.1

Hasil Breusch Godfrey Serial Correlation LM Test

\begin{tabular}{|c|c|c|}
\hline Model & Obs*R-squared & Prob \\
\hline$\Delta Y_{t}=\mu+\phi Y_{t-1}+e_{t}$ & 6.819718 & 0.033046 \\
\hline
\end{tabular}

Sumber : Hasil Pengolahan Data

Dengan nilai prob $=0.033046<\alpha=0.05$, maka hipotesis nol yang menyatakan tidak ada autokorelasi pada residual ditolak, sehingga disimpulkan terdapat autokorelasi pada residual. Berdasarkan hal tersebut, maka uji akar unit yang tepat untuk digunakan adalah Uji Akar Unit Phillips-Peron.

Jika memperhatikan plot data inflasi yang ditampilkan pada gambar 3.1, secara visual dapat disimpulkan bahwa data inflasi mempunyai trend naik, sehingga memperlihatkan sifat non stasioneritas. Dengan menggunakan uji Akar Unit PhillipsPeron, hasilnya diberikan pada tabel 3.2.

Tabel 3.2 Hasil Uji Akar Unit Phillips-Perron (PP)

\begin{tabular}{|c|c|c|c|}
\hline Variabel & Nilai PP( $\left.Z_{t}\right)$ & $\mathbf{P P}($ Critical Value 5\%) & Probabilita \\
\hline inflasi & -0.665458 & -2.960411 & 0.8410 \\
\hline
\end{tabular}

Sumber : Hasil Pengolahan Data 
Berdasarkan pada tabel 3.2 di atas, pada tingkat signifikansi $\alpha=0.05$, nilai $\mathrm{PP}=-1.222675$ $>$ Nilai kritis PP $=-2.960411$, sehingga hipotesis nol yang menyatakan bahwa data inflasi bersifat stasioner ditolak. Sehingga diambil kesimpulan bahwa data inflasi tidak stasioner.

\section{Penutup}

Stasioneritas merupakan asumsi penting yang harus dipenuhi dalam analisis ekonometrika. Salah satu uji stasioneritas adalah menggunakan uji akar unit. Untuk melakukan uji akar unit terhadap data yang mengandung autokorelasi pada residual digunakan uji akar unit Phillips-Perron (PP). Pada data inflasi di Indonesia pada periode 1996-2003 diperoleh kesimpulan bahwa data tidak stasioner sehingga perlu dilakukan uji derajat integrasi sebagai uji lanjutan untuk menentukan pada derajat integrasi keberapa data inflasi akan stasioner.

\section{DAFTAR PUSTAKA}

1. Bank Indonesia, Statistika Ekonomi dan Keuangan Indonesia, Bank Indonesia, Jakarta, 2003. URL:http://www.bi.go.id

2. Dickey, D.A. and Fuller, W.A., Distribution of the Estimators for Autoregressive Time Series with a Unit Root, Journal of American Statistical Association, 74: 427-443, 1979.

3. Enders, W., Applied Econometrics Time Series, John Wiley \& Sons, New York, 2005.

4. Granger, C.W.J. and Newbold P., Spurious Regression in Econometrics, Journal of Econometrics, 2:111-120. 1974

5. Gujarati, D., Basics Econometrics, McGraw-Hill International Editions, New York, 2000.

6. Haldrup, N. and Jansson, M., Improving Size and Power in Unit Root Testing, Working Paper No. 2005-02, University of Aarhus, Denmark, 2005.

7. Maruddani, D.A.I., Model Regresi Non Stasioner dengan Variabel Dependen Lag, Tesis S2 Jurusan Matematika, FMIPA, UGM, Yogyakarta, 2003, Tidak Dipublikasikan.

8. Maruddani, D.A.I., Wilandari, Y., dan Safitri, D., Pendekatan Error Correction Model untuk Pembentukan Model Empirik Pertumbuhan Ekonomi Indonesia Pasca Krisis Moneter, Laporan Penelitian DIK RUTIN, 2005, Tidak Dipublikasikan.

9. Maruddani, D.A.I., Wilandari, Y., dan Safitri, D., Model Dinamik Pertumbuhan Ekonomi Indonesia Pasca Krisis Moneter : Suatu Pendekatan Koreksi Kesalahan Model Dinamik Pertumbuhan Ekonomi Indonesia Pasca Krisis Moneter : Suatu Pendekatan Koreksi Kesalahan, Jurnal Sains dan Matematika, FMIPA UNDIP, 2007, 15:121-127.

10. Phillips, P.C.B., Time Series Regression with a Unit Root, Econometrica, 55:277-301, 1987.

11. Phillips, P.C.B. and Perron, P., Testing for a Unit Root in Time Series Regression, Biometrica, 75:335-346, 1988.

12. Sorensen, Unit Root, 2005. URL:http//www.unitroot.com

13. Thomas, R.L., Modern Econometrics - an Introduction, Addison Wesley, England, 2005.

14. Tsay, R.S., Analysis of Financial Time Series, second edition, John Wiley \& Sons Inc, Chicago, 2005. 
Media Statistika, Vol. 1, No. 1, Juni 2008: 27-34

15. Wei, W.W.S., Time Series Analysis, Addison-Wesley Publishing Company Inc, USA, 1994.

16. Widarjono, A., Ekonometrika Teori dan Aplikasi untuk Ekonomi dan Bisnis, edisi kedua, Ekonosia, Universitas Islam Indonesia, Yogyakarta, 2007 